\title{
A ANEEL E A POLÍTICA REGULATÓRIA EXTRAFISCAL SOBRE CÉLULAS FOTOVOLTAICAS: UMA SAÍDA PARA O DESENVOLVIMENTO SUSTENTÁVEL NO BRASIL?
}

\author{
Henrique Ribeiro Cardoso ${ }^{1}$ \\ Francisco Joaquim Branco de Souza Filho
}

\section{RESUMO:}

A necessidade de se promover o desenvolvimento sustentável com intenção de preservar ecossistemas através de políticas públicas das mais variadas, fez com que o comércio de células fotovoltaicas passasse a ser o grande foco de exploração econômica, patrocinando a narrativa de energia limpa, barata e sustentável. Todavia, a política regulatória da ANEEL sobre produtores individuais de células fotovoltaicas, prejudica o segmento econômico, motivo pelo qual representantes do setor de energia solar defendem a incorporação dos benefícios da modalidade na análise regulatória na atualização do modelo normativo no País, atualmente prejudicando a competitividade e o desenvolvimento econômico e sustentável no Brasil.

PALAVRAS-CHAVE: ANEEL; Desenvolvimento sustentável; Energia solar; Incentivos fiscais; Regulação Extrafiscal.

\section{ANEEL AND EXTRAFISCAL REGULATORY POLICY ON PHOTOVOLTAIC CELLS: IS IT A SUSTAINABLE DEVELOPMENT IN BRAZIL?}

\begin{abstract}
The need to promote sustainable development with the intention of preserving ecosystems through the most varied public policies, made the trade in photovoltaic cells become the major focus of economic exploration, sponsoring the narrative of clean, cheap and sustainable energy. However, ANEEL's regulatory policy on individual producers of photovoltaic cells harms the economic segment, which is why representatives of the solar energy sector advocate the incorporation of the benefits of the modality in the regulatory analysis in the updating of the regulatory model in the country, currently impairing competitiveness and economic and sustainable development in Brazil.
\end{abstract}

KEYWORDS: ANEEL; Extrafiscal regulation; Sustainable development; Solar energy; Tax breaks.

\footnotetext{
* Doutor em Direito e Cidadania (UGF/Rio); Pós-doutor em Direitos Humanos (IGC); Pós-doutor em Direitos Humanos (UFPB); Professor de Pós-graduação (UFS); Professor de Pós-graduação da UNIT; Promotor de Justiça em Sergipe. Av. Oviedo Teixeira, nº 120, ap. 901. Mansão Margarida Franco Diniz Jardins. Aracaju/SE. CEP: 49026-100. E-mail: henrique@mpse.mp.br

**Graduado em Direito pela Universidade Tiradentes. Pós-graduado em Direito Civil e Processo Civil pela Universidade Tiradentes. Especialista em Direito Tributário pela Rede Anhanguera de Ensino. Advogado e Professor Universitário e de cursinhos preparatórios para concursos e OAB. Av. Paulo VI, nº. 239, Inácio Barbosa, Aracaju/SE, CEP 49040-460. E-mail: franciscobrancoadv@ outlook.com
} 


\section{INTRODUÇÃO}

A relação homem e meio ambiente nunca esteve tão em foco como atualmente. Convenções, metas e programas de incentivos continuam sendo traçados nos quatro cantos do planeta como forma de frear o progresso desordenado e o desequilíbrio evolutivo que transformaram a Terra, motivo pelo qual o desenvolvimento tecnológico é uma realidade inarredável para se construir um Estado socialmente responsável e economicamente sustentável, no intuito de proporcionar progresso e bem-estar a sociedade de modo geral.

Nesse sentido, o Estado tem o dever de desenvolver políticas públicas que proporcionem um ambiente de negócios plausível, focado na constante modernização das relações econômicas e sociais, especialmente para tornar a atividade produtiva dinâmica e inovadora.

Todavia, esse conjunto de incentivos à inovação passa por uma clara indução de comportamento preconizado pela política regulatória extrafiscal do Estado Brasileiro ao conferir prerrogativas à produção de tecnologias sustentáveis, principalmente no tocante ao comércio de células fotovoltaicas patrocinando a narrativa do oferecimento de energia limpa, barata, eficiente e sustentável.

Mesmo no emaranhado de diversos incentivos fiscais no tocante a importação e aquisição desses módulos fotovoltaicos, produtores nacionais deste segmento econômico questionam a forma como a política regulatória tem sido exercida no Brasil, prejudicando a produção nacional, a empregabilidade e a geração de renda, fato este que nos leva a questionar até que ponto a política regulatória consegue, de fato, conferir desenvolvimento econômico sustentável e responsabilidade social?

Nesse sentido, a Teoria Discursiva do Direito e da Democracia Deliberativa, pautada na Ética do Discurso e que busca a promoção do agir comunicativo, em que atos de fala regulativos devem ser validados pelo atendimento de certas condições como a inteligibilidade, a pretensão de verdade, a pretensão de sinceridade e a pretensão de correção normativa, fazendo com que a participação dos atingidos por eventuais normas seja valorizada, num modelo positivo de liberdade, sem postergar, entretanto, a segurança jurídica. 
Por esta razão, foi criado no ano de 2014 pelo Governo Federal o PADIS - Programa de Apoio ao Desenvolvimento Tecnológico da Indústria de Semicondutores e Displays - que consiste num conjunto de incentivos fiscais federais instituído com o objetivo de contribuir para a atração e ampliação de investimentos nas áreas de semicondutores e displays. Esses incentivos incluem células e módulos fotovoltaicos para energia solar, além de alguns insumos estratégicos para a cadeia produtiva, como o silício purificado que, não obstante os incentivos fiscais conferidos, ainda constituem uma medida modesta de estratégia regulatória para o desenvolvimento desse tipo de segmento econômico nacionalmente, desproporcional ao grau de incentivo referente ao mesmo tipo de tecnologia importada.

É nesse contexto que ganha relevância a análise concomitante do sentido contemporâneo de desenvolvimento econômico sustentável conferido por Jeffrey Sachs e Amartya Sen, sob a perspectiva da fraternidade como categorização jurídica tendente à sua efetividade, vinculando, assim, os direitos de terceira dimensão, se fazendo necessário examinar como a tributação pode servir de instrumento à realização dos direitos fundamentais, dos direitos sociais e econômicos.

Portanto, busca-se esclarecer a caracterização da política regulatória, da extrafiscalidade, os conceitos de inovação tecnológica, e como esse fenômeno regulatório é aplicado às inovações de acordo com as leis de incentivo fiscal, passando por uma crítica a forma como a política regulatória extrafiscal tem sido exercida sobrea importação de painéis para produção de energia solar em detrimento da produção nacional de células fotovoltaicas e seus insumos para este segmento, ensejando uma produção pouco estimulante do desenvolvimento econômico nacional sustentável, a empregabilidade e a geração de renda no Brasil.

\section{POLÍticas PÚblicas PARA A PRODUÇÃo E O COMÉRCIO dE CÉlulas FOTOVOLTAICAS COMO UMA FORMA DE TUTELA DE DIREITOS DIFUSOS E COLETIVOS:}


A difusão de políticas, no caso de proteção ambiental e incentivo à produção, é o processo segundo o qual uma inovação é comunicada por meio de certos canais ao longo do tempo entre membros de um sistema social (ROGERS, 2003, p. 03).

Em razão disso, os estudos de difusão se iniciam com uma descrição dos padrões de adoção de certas inovações de policies ao decorrer do tempo, analisando quais os fatores significativos que levaram a essa disseminação. Assim, sem se focar nas razões tipicamente intrínsecas das fases de uma política pública - da identificação do problema e formação da agenda até a avaliação da política - a difusão anseia identificar quais fatores que influenciaram essas fases sendo comuns a todos os adotantes de uma política ao longo do tempo, demonstrando também quais fatores externos comuns impactam nesse processo (ANASTÁCIO, 2017, p. 1-23).

Nesse sentido, a forma de pensar o meio ambiente atualmente se constitui na maturidade de afastar ideia do individualismo antropocêntrico da titularidade de direitos humanos. Vencidas as etapas iniciais de afirmação e desenvolvimento dos direitos humanos fundamentais, sobre o prisma da liberdade e igualdade em decorrência das conquistas inerentes aos direitos civis, políticos, sociais, econômicos e culturais, alcança-se a terceira geração de direitos, pautado no dever de fraternidade (ou solidariedade) que, como lembra Ingo Wolfgang Sarlet (SARLET, 2004, p. 56 e 57), caracterizando-se pelo fato de se desprenderem, em princípio, da figura do homem-indivíduo como seu titular, destinando-se à proteção de grupos humanos (família, povo, nação), e caracterizando-se, consequentemente, como direitos de titularidade coletiva ou difusa.

Nesse sentido, Carlos Augusto Alcântara Machado ${ }^{3}$, em análise correlata entre as dimensões do Direito e os princípios formuladores das pretensões revolucionárias francesas, aduz que nessa categoria jurídica, como direitos de terceira dimensão - direitos de fraternidade - inserem-se os direitos à paz, ao meio ambiente, à autodeterminação dos povos, trazendo como como nota distintiva a marca universalidade, ou, quando menos, a característica de transindividualidade ou metaindividualidade.

Em razão disso, na Carta de 1988 o legislador constituinte brasileiro, ao se comprometer com a construção de uma sociedade fraterna, pluralista e sem preconceitos, e

\footnotetext{
${ }^{3}$ MACHADO, Carlos Augusto Alcântara. Constitucionalismo Fraternal. Revista Diálogos Possíveis, Salvador. Ano 14.
} 
indicar os valores que darão concretude ao compromisso, estabeleceu os objetivos fundamentais da República Federativa. Dentre eles, o primeiro, especialmente, deu densidade normativa à promessa do preâmbulo: a construção de uma sociedade solidária (art. $3^{\circ}$, I $\mathrm{CF} / 88)^{4}$.

É nesse contexto que o pensamento verde $e^{5}$ vem ganhando mais espaço na tutela e implementação de tecnologias voltadas a proteção ambiental e a exploração econômica sustentável, reduzindo sobremaneira a degradação do meio ambiente sem prejuízo do desenvolvimento econômico e social.

Por essa razão, a produção e o comércio de módulos fotovoltaicos para produção de energia solar consistem um dos mais promitentes segmentos econômicos para a instituição e desenvolvimento de energia renovável, limpa, sustentável, barata e eficiente, no Brasil, isto porque a eficiência energética de um painel solar é equivalente à da energia elétrica convencional operada pelas concessionárias de serviço público de distribuição de energia ${ }^{6}$.

Nesse sentido, é inegável o interesse de produtores industriais de dentro e fora do Brasil sobre esse tipo de segmento, mormente vinculado ao discurso contemporâneo de sustentabilidade econômica e preservação ambiental, fazendo com que este ramo passasse a ser foco de inúmeros incentivos fiscais por parte do Governo Federal.

Em razão disso, foi criado em 2014, o PADIS - Programa de Apoio ao Desenvolvimento Tecnológico da Indústria de Semicondutores e Displays - que consiste num conjunto de incentivos fiscais federais instituído com o objetivo de contribuir para a atração e ampliação de investimentos nas áreas de semicondutores e displays, introduzindo, por exemplo, a instituição de alíquotas zero para contribuições como o PIS e a COFINS, Imposto sobre Produtos Industrializados (IPI) e Imposto de Importação (II), todos eles incidentes na importação de máquinas, instrumentos e equipamentos para incorporação ao ativo imobilizado final do adquirente, além softwares e tantos outros insumos empregados na

\footnotetext{
${ }^{4}$ MACHADO, Carlos Augusto Alcântara. Constitucionalismo Fraternal. Revista Diálogos Possíveis, Salvador. 2014.

${ }^{5}$ Pensamento verde: brocardo popularmente utilizado para se referir equipamentos, instrumentos, teorias e artifícios tecnológicos voltados a proteção ambiental.

${ }^{6}$ A eficiência de um painel solar é basicamente a porcentagem de energia da luz do sol que o painel solar converte em energia elétrica por $\mathrm{m} 2$. Ou seja, um painel solar com eficiência de $16.5 \%$ converte $16.5 \%$ da energia que incide sobre o painel, por m2, em energia elétrica. Fonte: INMETRO.
} 
produção dos módulos fotovoltaicos, demonstrando claramente o protagonismo do Estado brasileiro como agente canalizador de uma política regulatória extrafiscal voltada a tutela desse tipo de tecnologia renovável em prol do desenvolvimento econômico sustentável.

Portanto há uma tendência de se promover a propagação de direitos transindividuais, como a tutela do meio ambiente ecologicamente equilibrado, pautados no interesse coletivo, solidário, fraterno, servindo como instrumento de propagação de direitos de terceira dimensão, e proteção as futuras gerações.

Nesse sentido, Alcântara Machado ${ }^{7}$ aduz que a própria Constituição da República Federativa do Brasil, promulgada em 05 de outubro de 1988, já havia adotado similar orientação, consagrando no seu pórtico, princípios/valores preliminares em sede de PREÂMBULO, introduzindo o articulado normativo com relevantes compromissos. O texto integral, materializado em eloquente invocação, obteve a seguinte redação (sem os grifos e destaques em maiúsculo):

\begin{abstract}
Nós, representantes do povo brasileiro, reunidos em Assembleia Nacional Constituinte para instituir um Estado Democrático, destinado a assegurar o exercício dos direitos sociais e individuais, a liberdade, a segurança, o bemestar, o desenvolvimento, a igualdade e a justiça como valores supremos de uma SOCIEDADE FRATERNA, pluralista e sem preconceitos, fundada na harmonia social e comprometida, na ordem interna e internacional, com a solução pacífica das controvérsias, promulgamos, sob a proteção de Deus, a seguinte CONSTITUIÇÃO DA REPÚBLICA FEDERATIVA DO BRASIL.
\end{abstract}

Por fim, contemplou o supremo legislador brasileiro a moldura jurídicoconstitucional de um Estado não mais comprometido com uma ideologia puramente liberal (Estado Liberal) ou social (Estado Social), ou até liberal-social, mas com a construção de um Estado Fraternal (BRITO, 2003, p. 207), motivo pelo qual a proteção ao meio ambiente atinge essa finalidade, urgindo a necessidade do Estado de promover políticas públicas essenciais para incentivo desse tipo de comportamento pautado na responsabilidade ambiental, de modo que uma de suas formas de incentivo dá-se através da relação fiscal.

\footnotetext{
${ }^{7}$ MACHADO, Carlos Augusto Alcântara. Constitucionalismo Fraternal. Revista Diálogos Possíveis, Salvador. Ano 14.
} 


\section{A EXTRAFISCALIDADE COMO INCENTIVO AO DESENVOLVIMENTO ECONÔMICO SUSTENTÁVEL SOBRE A PRODUÇÃO NACIONAL DE CÉLULAS FOTOVOLTAICAS E CRÍTICAS AO MODELO DE INCENTIVO ATUAL:}

É inegável que a revolução industrial trouxe em seu bojo a ideia de maximização dos rendimentos pelo menor custo possível, com a finalidade de suprir um mercado de serviços e bens de consumo voraz. De lá para cá, o homem vem utilizando os recursos naturais com a finalidade econômica, de modo que apenas nas últimas décadas é que políticas públicas têm sido implementadas para controlar a degradação ambiental e a poluição de séculos.

Imparcial aos argumentos ideológicos voltados ao prejuízo provocado a intervenção do Estado na atividade econômica ou qualquer outra adversidade de cunho neoliberal ou mesmo estadista, um dado é certo, o Estado é agente crucial na canalização de comportamentos dos seus súditos, de modo que na sustentabilidade não é diferente.

Em verdade, um dos principais objetivos da atividade fiscal do Estado é a captação de recurso para os cofres públicos, como instrumento essencial para se promover a concretização das garantias constitucionais, manutenção da máquina pública e compromissos firmados com a ordem constitucional. A chamada extrafiscalidade tributária, por outro lado, diz respeito ao fato de se utilizar da coerção do pagamento dos impostos, com o intuito de estimular, induzir ou até mesmo coibir contribuintes, aplicando-se as receitas não apenas com a intenção arrecadatória para sanar despesas públicas ${ }^{8}$, mas induzindo comportamentos.

Ao contrário da fiscalidade, o fenômeno da extrafiscalidade não está vinculado a ideia meramente arrecadatória, isto é, o singelo interesse de engrandecimento do Erário Público, mas constituindo um importe instrumento no direcionamento de comportamentos de seus contribuintes.

Geraldo Ataliba (ATALIBA, 1990, p. 233.), nesse contexto, define claramente a essência da extrafiscalidade:

\footnotetext{
${ }^{8}$ LOPES, Andréia Regina Ubeba, PORTUGAL, Heloisa Helena de Almeida, CARDOSO, Sergio, Investimento em Crédito de Carbono: Possibilidade Tributária, disponível em: http://www.diritto.it/archivio/1/27676.pdf, acesso em: 20 out. 2016.
} 
Consiste a extrafiscalidade no uso de instrumentos tributários para obtenção de finalidades não arrecadatórias, mas estimulantes, indutoras ou coibidoras de comportamentos, tendo em vista outros fins, a realização de outros valores constitucionalmente consagrados. [...] É lícito recorrer aos tributos com o intuito de atuar diretamente sobre os comportamentos sociais e econômicos dos contribuintes, seja fomentando posicionamento ou inibindo certos procedimentos. Dá-se tal fenômeno (extrafiscalidade) por intermédio de normas que, ao preverem uma tributação, possuem em seu bojo, uma técnica de intervenção ou conformação social por via fiscal. São os tributos extrafiscais, que podem ser traduzidos em agravamentos ou benefícios fiscais dirigidos ao implemento e estímulo de certas condutas.

O fato é que sempre que se fala em intervenção ou mesmo manipulação do Estado sobre a atividade econômica - e a relação extrafiscal detém essa aptidão - tal tipo de conjectura nem sempre é vista com bons olhos, tendo em vista catastróficas experiências desse tipo de ação na história do Brasil.

Perceba, por exemplo, a clareza de como os efeitos da extrafiscalidade sobre o IPI pode interferir diretamente na balança comercial do país, como comenta Flávio de Azambuja Berti (BERTI, 2012, p. 79-85.):

[...] imagine-se que manter um saldo positivo na balança comercial é conveniente para o país, o que efetivamente é verdade. Ora, tal saldo só é passível de ocorrer se as indústrias brasileiras aumentarem seus volumes de vendas ao exterior. Este objetivo pode ser estimulado pelo fisco de algumas formas diferentes: a) mediante uma tributação menor sobre as exportações (observe-se que há imunidade do IPI para vendas ao exterior, conforme previsto no texto do art. 153 da $\mathrm{CF} / 88$ ); b) através de subsídios financeiros para empresas exportadoras; c) com a abertura de linhas especiais de financiamento para a exportação; d) através do uso de outros benefícios fiscais para os exportadores, por exemplo, créditos presumidos para o IPI sobre a parcela de bens não exportados e vendidos no país ou mesmo para serem usados na compensação de outros tributos federais no caso de a indústria exportar praticamente toda sua produção. 
Como aduzido por Flávio Marcelo Rodrigues Bruno e Liziane Paixão Silva Oliveira em obra recente, sobre o amparo de HOEKMAN e KOSTECKI, 1995, a intervenção estatal na economia pode reduzir a eficiência econômica. Mas no caso de se manifestarem externalidades, a intervenção estatal pode realmente aumentar a eficiência econômica e aumentar o bem-estar da sociedade. O modo como o governo intervém é extremamente importante, por isso uma análise econômica lançada sobre as políticas de intervenção na economia garantiria que os programas estatais sejam economicamente o mais eficiente possível (BRUNO, 2015, p.255-269)

Seja de um modo ou de outro, um dado é certo, através da política regulatória extrafiscal o Estado passa a induzir determinados comportamentos aos contribuintes e esses comportamentos refletem a pretensão do governo sobre determinado aspecto político, econômico, social e cultural, de modo que na responsabilidade socioambiental para instituição de mecanismos que propiciem o desenvolvimento econômico sustentável não é diferente.

Mas até que ponto esse tipo de proposta é viável?

No final de Julho de 2020, a CAMEX ${ }^{9}$ - Câmara do Comércio Exterior - publicou um ato normativo de redução do valor das alíquotas de imposto de importação para equipamentos fotovoltaicos, demonstrando clara atividade extrafiscal. Ao todo, foram incluídos mais de 100 Ex-Tarifários ${ }^{10}$ relacionados a módulos solares, inversores, displays e demais insumos. A medida entrou em vigor em $1^{\circ}$ de agosto e será válida até o final de 2021.

Todavia, muitos fabricantes nacionais criticam o fasto de não estarem sendo beneficiados com tais incentivos já que, atualmente, os módulos importados têm isenção de IPI e Imposto sobre Circulação de Mercadorias e Serviços (ICMS), além de PIS/ COFINS,

\footnotetext{
${ }^{9}$ Instituída pela Lei $n^{\text {o }}$. 13.844/19 e Decreto $n^{\circ}$ 10.044/19, a Câmara de Comércio Exterior - Camex - faz parte do Ministério da Economia e tem por objetivo a formulação, a adoção, a implementação e a coordenação de políticas e de atividades relativas ao comércio exterior de bens e serviços, aos investimentos estrangeiros diretos, aos investimentos brasileiros no exterior e ao financiamento às exportações, com vistas a promover o aumento da produtividade da economia brasileira e da competitividade internacional do País.

${ }^{10} \mathrm{O}$ regime de ex-tarifários visa estimular os investimentos para ampliação e reestruturação do setor produtivo nacional de bens e serviços, por meio da redução temporária do Imposto de Importação de bens de capital e bens de informática e telecomunicações sem produção no Brasil. Cabe ao Comitê de Análise de ex-tarifários (Caex) verificar a inexistência de produção nacional e o mérito dos pleitos tendo em vista os objetivos pretendidos, os investimentos envolvidos e as políticas governamentais de desenvolvimento.
} 
enquanto as empresas nacionais são tributadas ao adquirir suas matérias-primas, pagando I.I, IPI, PIS/COFINS e ICMS, o que vem prejudicando a competitividade nacional.

Sendo assim, em que pese a boa pretensão sobre a política regulatória extrafiscal neste tipo de segmento econômico, é perceptível que na realidade ela só atinge a um específico ramo de atividade produtiva e comércio, qual seja a importação desses equipamentos e seus insumos para serem consumidos no território nacional, fazendo com que a produção interna nacional fique desprestigiada quanto a tais incentivos, prejudicando o desenvolvimento econômico sustentável, a empregabilidade e a geração de renda, constituindo uma medida de gestão fiscal contraditória ao se levar em consideração as reservas minerais que poderiam colocar o Brasil como líder das energias limpas no mundo.

Conforme dispõe Jeffrey Sachs (SACHS, 2013, p. 01), há três razões incontornáveis para o mundo fazer a mudança para uma energia de baixo carbono. Em primeiro lugar, a elevação dos níveis de CO2 está acidificando os mares da Terra, de modo que se mantivermos nossos velhos hábitos, acabaremos destruindo uma enorme parte da vida marinha, o que comprometerá severamente as cadeias alimentares das quais dependemos.

Em segundo lugar, o CO2 está mudando perigosamente o clima do mundo, por mais que os interesses dos grandes conglomerados do petróleo tentem nos convencer do contrário.

Em terceiro lugar, estamos diante da alta significativa dos preços dos combustíveis fósseis, num momento em que o crescimento dos países em desenvolvimento eleva a demanda e se esgotam as fontes convencionais de carvão, petróleo e gás. Podemos, seguramente, encontrar mais combustíveis fósseis, mas a um custo muito mais alto e com um risco ambiental muito maior, decorrente de contaminações industriais, resíduos, vazamentos e outros estragos.

De acordo com Sachs, o desenvolvimento sustentável é, para além de uma ideia, uma referência atualmente. É uma maneira de entender o mundo e um método de resolver os problemas globais. Os Objetivos do Desenvolvimento Sustentável devem propiciar um crescimento econômico socialmente inclusivo e ambientalmente sustentável ${ }^{11}$. Para se alcançar esses objetivos econômicos, sociais e ambientais, deve estar presente a boa governança (SACHS, 2015, p. 03), circunstância em momento algum observada no Brasil no

\footnotetext{
${ }^{11}$ SACHS, Jeffrey. The age of sustainable development. New York: Columbia University Press, 2015. p. 3.
} 
tocante ao desenvolvimento sustentável local sobre os módulos fotovoltaicos, não em razão da inexistência de políticas regulatórias de incentivos fiscais, mas pelo seu mal posicionamento, uma vez que beneficia a produção e a tecnologia importadas em detrimento da produção e pesquisa nacionais.

Para se ter uma ideia, o Brasil é detentor das maiores reservas mundiais de quartzo, mineral utilizado para fabricação do silício, que por sua vez é utilizado na fabricação de células fotovoltaicas. Mesmo diante dessa condição, o Brasil importa as lâminas de silício utilizadas na fabricação dos painéis fotovoltaicos. O Estado brasileiro exporta o silício metalúrgico a US\$ 2 o quilo. Depois de purificado no exterior é transformado em lâminas usadas na fabricação de semicondutores ou células fotovoltaicas que custam entre US\$ 50 e US\$1.000, dependendo da pureza e da cristalinidade ${ }^{12}$.

Nesse contexto, percebe-se uma clara desproporcionalidade na forma de como esse tipo de segmento econômico tem sido pessimamente explorado no Brasil, motivo pelo qual nos leva novamente a questionar, até que ponto a política regulatória de incentivos fiscais está sendo, de fato, viável para o desenvolvimento econômico sustentável internamente?

Ao se instituir uma proposta de incentivos fiscais para o desenvolvimento econômico sustentável, deve-se avaliar a importância do impacto desse desenvolvimento nacionalmente, o que não se observa na produção desse tipo de tecnologia no Brasil, em razão da alta tributação sobre os insumos sobre a respectiva cadeia de produção de células fotovoltaicas.

Nas preciosas lições de Amartya Sem (SEN, 2000, p. 409), o desenvolvimento pode ser encarado como um processo de alargamento das liberdades reais, da promoção do potencial humano como centro das políticas de desenvolvimento e a superação das diversas formas de privação, que acabam por limitar o potencial humano e subjugar o homem ao capital.

É o que ocorre no Brasil. A forma como a política regulatória de incentivos fiscais sobre esses equipamentos tem sido realizada internamente, ao invés de propiciar o desenvolvimento econômico local, tem subjugado a produção nacional as vontades do capital estrangeiro no mercado interno.

\footnotetext{
${ }^{12}$ https://revistapesquisa.fapesp.br/silicio-brasileiro-para-celulas-solares (acessado em 08/12/2020).
} 
Nesse contexto, Amartya Sen atenta para esse tipo de comportamento maculador da liberdade de forma de subjuga-la ao mero poder do capital, estabelecendo que a liberdade não é exclusivamente um fim primordial do desenvolvimento, mas também seu principal meio, motivo pelo qual sistematiza a sua amplitude constitutiva e instrumental, esta como meio para o desenvolvimento e a sua expansão, aquela, ligada a liberdade como objetivo de avaliação.

O papel constitutivo relaciona-se a importância da liberdade substantiva no enriquecimento da vida humana (...). Nessa perspectiva constitutiva o desenvolvimento envolve a expansão dessas [liberdades substantivas] e de outras liberdades básicas: é o processo de expansão das liberdades humanas (...) O papel instrumental da liberdade concerne ao modo como diferentes tipos de direitos, oportunidades e intitulamentos contribuem para a expansão da liberdade humana em geral, e assim, para a promoção do desenvolvimento. (SEN. 2000, p. 55-56)

Nesse mesmo sentido a Constituição Federal de 1988 conferiu em seu art. 3º, II, como norma programática e fundamental da República Brasileira, a garantia do desenvolvimento nacional, constituindo uma meta a ser galgada pelo Brasil, em sua vasta acepção, de modo que aliado a Preâmbulo Constitucional ao estabelecer, dentro outros, o desenvolvimento, como valor supremo de uma sociedade fraterna, pluralista e sem preconceitos, tais regra canalizam os anseios do legislador constituinte no tocante ao aspecto agregador que deve haver tomada de decisões vinculadas ao desenvolvimento econômico interno, circunstância esta não observada no contexto da política regulatória de incentivos fiscais da produção brasileira de equipamentos fotovoltaicos, focada, por sua vez, no contexto permissivo do capital externo.

Como assinala Sen, uma abordagem adequada do desenvolvimento não pode se concentrar apenas nos detentores do poder, devendo ter maior abrangência, exigindo efetiva participação cidadã nos processos decisórios (SEN, 2000, p. 174).

É nesse contexto que, mesmo já tendo uma política pública para incentivar a instalação de painéis solares, decorrente da institucionalização do PADIS, é preciso respostas mais concretas do governo para identificação desses obstáculos que emperram o desenvolvimento do setor interno, além de ações legiferantes para modificação desse cenário, à título de se proporcionar uma maior isonomia fiscal e competitividade da produção nacional 
desse tipo de tecnologia, como é o exemplo da apuração do projeto de lei (PL) 4.805/2019, em tramitação no Congresso Nacional, que dispõe sobre a política industrial para o setor de tecnologia da informação e comunicação, bem como para semicondutores, aperfeiçoando o PADIS e os seus anexos, ampliando os incentivos fiscais por ele proporcionado aos insumos para o desenvolvimento da produção nacional de células fotovoltaicas, capaz, desse modo, de conferir verdadeiro desenvolvimento econômico sustentável, gerando empregos e renda, a partir de um caráter inclusivo da indústria nacional e não permissiva ao capital externo.

Uma estimativa da Secretaria do Trabalho, cuja estrutura atual é integrada ao Ministério da Economia em decorrência da MP nº. 870/2019, aduz que o Brasil está entre os cinco países que mais criam empregos com esse tipo de geração energia, de modo que o aumento da importação das células e módulos fotovoltaicos constitui na realidade um risco a esse protagonismo nacional na sustentabilidade, já que se não houver o contorno dessas distorções tributárias, o país sofrerá com a baixa competitividade de sua produção, prejudicando investidores e outros fabricantes, nacionais ou estrangeiros, que possuem a pretensão de se instalar no Brasil e assim gerar empregos em diversos setores industriais nas diversas áreas de atuação.

É nesse contexto que a crítica ao modelo de política regulatória de incentivos ficais a este tipo de segmento ganha importância pois, em verdade, não se está concebendo a essência da liberdade do desenvolvimento econômico sustentável, ao contrário, o discurso da sustentabilidade passa a ser utilizado como subterfúgio a clara criação de um privilégio em prol do interesse do capital externo em detrimento da produção, do desenvolvimento e sustentabilidade econômica nacional.

Por conta disso, se justificam os olhares atentos dos produtores nacionais de módulos fotovoltaicos ao projeto de lei (PL) $n^{\circ} 4.805 / 2019$, uma vez que o projeto traz um novo modelo de incentivos fiscais para empresas de tecnologia da informação e comunicação e de semicondutores, no sentido de melhor conferir isonomia no tratamento fiscal a indústria nacional, bem como de investimento em pesquisa e desenvolvimento deste segmento econômico no Brasil, na tentativa de propiciar, de fato, sustentabilidade econômica interna, garantindo, assim, sua integração com o discurso da política regulatória extrafiscal, vislumbrando a necessidade de construção de cidades mais inteligentes e renováveis. 
Esse processamento inteligente servirá como referência e norteará as tomadas de decisões de empresas, governos e cidadãos, com o intuito de tornar as atividades urbanas mais eficientes e sustentáveis nas esferas econômica, social, ecológica e política (LEMOS, 2013, p. 87).

Por fim, o que se pretende com a inserção do fenômeno da extrafiscalidade na tributação ambiental é aliar a pretensão do Estado Brasileiro como garantidor da sustentabilidade e proteção de um meio ambiente equilibrado, tal como disposto no art. 225 da $\mathrm{CF} / 88$, sem deixar de propiciar o desenvolvimento econômico interno, agindo o Estado como principal canalizador desse tipo de comportamento.

\section{DA POLÍtica REgUlatória dA ANEEL SOBRE O SISTEMA DE DISTRIBUIÇÃo DE ENERGIA E O COMÉRCIO DE CÉlulas FOTOVOLTÁICAS:}

Emaranhando essa necessidade de desenvolvimento econômico mediante fontes de energia barata, abundante e sustentável, a ANEEL, ao que indica, atua na contramão de direção - ou ao menos atuava - a partir do estabelecimento de políticas regulatórias que não transparecem a pretensão de verdade e correção normativa dos interesses difusos e coletivos sobre o respectivo segmento econômico.

O fato é que desde 17 de abril de 2012, quando entrou em vigor a Resolução Normativa ANEEL n ${ }^{\circ} 482 / 2012$, o consumidor brasileiro passou a gerar sua própria energia elétrica a partir de fontes renováveis ou cogeração qualificada e inclusive fornecer o excedente para a rede de distribuição de sua localidade. Trata-se da micro e da minigeração distribuídas de energia elétrica, inovações que podem aliar economia financeira, consciência socioambiental e autossustentabilidade.

O problema é que a referida resolução está sendo objeto de discussão atual que coloca xeque esse cenário promissor. A revisão da resolução normativa 482/2012, da Agência Nacional de Energia Elétrica (ANEEL), muda o sistema de tarifação para quem utiliza sistemas de geração distribuída, repercutindo diretamente no cenário econômico das células 
fotovoltaicas. De acordo com o texto proposto, quem produz e consome sua própria energia passará a pagar pelo uso da rede de transmissão e distribuição, popularmente denominada de "tarifa do fio", circunstância esta que onera não apenas a distribuição do potencial de energia elétrica, mas também todos os insumos e instrumentos que perfazem neste segmento econômico.

Para se ter uma ideia, uma instalação fotovoltaica residencial, cujo investimento seria compensado em quatro anos, passa a ter payback de até oito anos, fazendo com que investir nesse tipo de energia deixa de ser interessante, passando a ser altamente oneroso, passando a

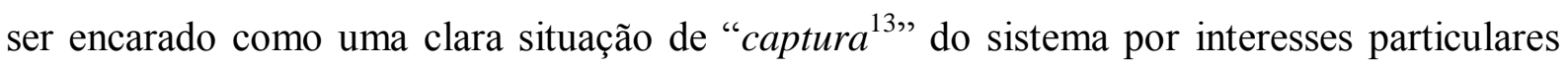
aparentemente escusos.

Nesse sentido, ganha amparo a análise da Teoria Discursiva do Direito e da Democracia Deliberativa, pautada na Ética do Discurso e que busca a promoção do agir comunicativo, em que atos de fala regulativos devem ser validados pelo atendimento de certas condições como a inteligibilidade, a pretensão de verdade, a pretensão de sinceridade e a pretensão de correção normativa, fazendo com que a participação dos atingidos por eventuais normas seja valorizada, num modelo positivo de liberdade, sem postergar, entretanto, a segurança jurídica, justamente no intuito de se evitar a aludida captura.

Em razão disso, a compreensão focada da discricionaridade compelida as agências reguladoras - no caso a ANEEL - ganha fundamentação relevância uma vez que o seu conteúdo decorre da determinação legal de buscar o melhor meio de satisfazer o interesse público. Como diria Celso Antônio Bandeira de Melo, não há espaço para qualquer comportamento fora da lei.

Neste cenário, leciona o professor Henrique Ribeiro Cardoso que a Teoria Discursiva do Direito, com sua correlata Democracia Deliberativa, não apresenta um projeto ambicioso de instituição de uma sociedade justa, mas parte da constatação das mudanças de paradigmas em diferentes ciências que repercutem na integração social e, especialmente, no direito.

\footnotetext{
${ }^{13}$ A teoria da captura do regulador recai sobre a teoria da escolha pública conhecido como regulação econômica, em que no dever de regular a atividade dos prestadores de serviços públicos, as agências passam a regular as condutas dos usuários de serviços em atendimento direto aos interesses particulares desses mesmos prestadores.
} 
Sendo assim, no horizonte atual em que a proposta do desenvolvimento econômico está vinculada a ideia de sustentabilidade, integração, cooperação e proteção ambiental, o estabelecimento de políticas regulatórias em contrassenso a este contexto infere uma ilegitimidade no exercício das atividades fins das agências reguladoras, mesmo porque fora desse contexto se estaria deturpando a análise prática da norma jurídica administrativa.

Aponta o mesmo acadêmico ainda que a produção do direito das agências reguladoras - atos administrativos regulatórios gerais e abstratos - é pautada pela liberdade de escolha de meios dentro do marco das leis de criação e atribuição de competências das agências reguladoras, em moldes semelhantes à atuação do legislador numa ordem constitucional marco, mas com a especificação de perseguirem as finalidades determinadas pela lei de criação e fixação de competência das agências reguladoras (CARDOSO, 2007, pg. 267).

Para ele, as regras do discurso compreendem regras da argumentação jurídica acerca da aplicação das regras do direito, somadas às regras específicas para a aplicação de diretrizes/objetivos/princípios, consubstanciadas na regra da proporcionalidade, englobadas nesta as sub-regras da adequação, da necessidade e da proporcionalidade em sentido estrito, abrangendo esta última sub-regra a lei de colisão e as denominadas regras da ponderação (CARDOSO, 2007, p. 268).

Sendo assim, a oneração da política regulatória da ANEEL sobre a produção e distribuição energética decorrente do segmento de células fotovoltaicas é totalmente dissonante a realidade de desenvolvimento econômico e sustentável da qual a proposta originária estaria atrelada, violando o contexto legal de legitimidade da política da respectiva agência reguladora, que por sua vez recai sobre a sua regulação extrafiscal.

\section{CONSIDERAÇÕES FINAIS}

Num contexto histórico, foi sob o prisma dos ideais revolucionários da Revolução Francesa de 1789 - liberdade, igualdade e fraternidade - que se constituiu o momento atual de comunhão de interesses difusos e coletivos, de modo que, vencidas as etapas iniciais de 
afirmação e desenvolvimento dos direitos humanos fundamentais, em decorrência das conquistas inerentes aos direitos civis, políticos, sociais, econômicos e culturais, alcança-se a terceira dimensão de direitos - direitos de fraternidade - caracterizado pelo fato de se desprenderem, em princípio, da figura do homem-indivíduo como seu titular, destinando-se à proteção de grupos humanos (família, povo, nação), e caracterizando-se, consequentemente, como direitos de titularidade coletiva ou difusa, não estando a proteção do meio ambiente fora desse tipo de conjectura.

Seguindo essa esteira, na Carta de 1988, o legislador constituinte brasileiro, ao se comprometer com a construção de uma sociedade fraterna, pluralista e sem preconceitos, passaram a indicar os valores que darão concretude ao compromisso, estabelecendo os objetivos fundamentais da República Federativa, dentre eles, a construção de uma sociedade solidária, agregando ao desenvolvimento nacional o viés de sustentabilidade e proteção ao meio ambiente, necessário a geração atual e legado para as futuras.

É nesse contexto que a política regulatória de incentivos fiscais age como protagonista na persecução do desenvolvimento econômico sustentável a partir da incentivos tributários para o desenvolvimento da produção nacional sobre o segmento de células e módulos fotovoltaicos, em decorrência dos efeitos da extrafiscalidade atuante como fenômeno presente na política regulatória de incentivos fiscais que recai sobre determinados tributos no Brasil, que possibilita uma maior margem de flexibilização a cominação de suas alíquotas, voltadas a necessidade de induzir a prática de determinados comportamentos dos contribuintes, adequando as pretensões fiscais do governo, dentre elas, a política de desenvolvimento econômico e ambiental sustentáveis.

Desse modo, ao se avaliar uma proposta de incentivos fiscais para o desenvolvimento econômico sustentável, deve-se avaliar a importância do impacto desse desenvolvimento nacionalmente, circunstância esta que não se observa na produção desse tipo de tecnologia no Brasil, em razão da alta tributação sobre os insumos na respectiva cadeia de produção de células fotovoltaicas, constituindo medida contraditória a política fiscal de comercio exterior para o mesmo tipo de equipamentos e para o próprio discurso da sustentabilidade, subjugando o interesse no desenvolvimento nacional nacional a pretensão do capital exterior sobre esse tipo de segmento econômico. 
Por outro lado, tutelado pelas lições de Amartya Sen, o desenvolvimento deve ser encarado como um processo de alargamento das liberdades reais, da promoção do potencial humano como centro das políticas de desenvolvimento e a superação das diversas formas de privação, que acabam por limitar o potencial humano e subjugar o homem ao capital.

É o que ocorre no Brasil. A forma como a política regulatória de incentivos fiscais sobre esses equipamentos tem sido realizada internamente, ao invés de propiciar o desenvolvimento econômico local, diminui e dificulta a liberdade da produção nacional em prol vontades do capital estrangeiro no mercado interno.

Em razão disso, mesmo já tendo uma política pública para incentivar a instalação de painéis solares, decorrente da institucionalização do PADIS, é preciso respostas mais concretas do governo para identificação desses obstáculos que emperram o desenvolvimento do setor interno, além de ações legiferantes para modificação desse cenário, à título de se proporcionar uma maior isonomia fiscal e competitividade da produção nacional desse tipo de tecnologia, conforme ora protagonizado pelo projeto de lei (PL) 4.805/2019, em tramitação no Congresso Nacional, dispondo sobre a política industrial para o setor de tecnologia da informação e comunicação, bem como para semicondutores, aperfeiçoando o PADIS e os seus anexos, ampliando os incentivos fiscais por ele proporcionado aos insumos para o desenvolvimento da produção nacional de células fotovoltaicas, capaz, desse modo, de conferir verdadeiro desenvolvimento econômico sustentável, gerando empregos e renda, a partir de um caráter inclusivo da indústria nacional e não permissiva ao capital externo.

Por conta disso é que o presente artigo critica o modelo de política regulatória de incentivos ficais a este tipo de segmento econômico pois, em verdade, não se concebe a essência da liberdade do desenvolvimento econômico sustentável, ao contrário, o discurso da sustentabilidade passa a ser utilizado como subterfúgio a clara criação de um privilégio em prol do interesse do capital de grupos econômicos internacionais em detrimento da produção, do desenvolvimento e sustentabilidade econômica nacional.

\section{REFERÊNCIAS BIBLIOGRÁFICAS}


- ANASTÁCIO, Kimberly. Difusão de Políticas Públicas \& amp; Tecnologia: expansão das Cidades Digitais no Brasil. $9^{\circ}$ Congresso Latino Americano de Ciência Política. Montevideo, 2017, p. 1-23.

- ATALIBA, Geraldo. IPTU: progressividade. Revista de Direito Público, v. 23, n. 93, 1990.

- BANDEIRA DE MELlo, Celso Antônio. Curso de Direito Administrativo. 23. ed. São Paulo: Malheiros Editores, 2010, p. 411.

- BERTI, Flávio de Azambuja. Impostos Extrafiscalidade e Não-Confisco. 3. ed. Curitiba: Juruá, 2012.

- BRASIL. Constituição (1988). Constituição da República Federativa do Brasil. Brasília, DF: Senado Federal.

- BRITTO, Carlos Ayres Britto, Teoria da Constituição, Rio de Janeiro: Forense, 2003.

- BRUNO, Flávio Marcelo Rodrigues. OLIVEIRA, Liziane Paixão Silva. Análise Econômica do Direito aplicada às medidas de intervenção estatal sobre os Créditos de Carbono. Visto em Veredas do Direito, Belo Horizonte. v.11. n.22. p.255-269.

- CARDOSO, Henrique Ribeiro. Controle da legitimidade da atividade normativa das agências reguladoras. Rio de Janeiro. Lumen Iuris. 2007.

- LEMOS, Andre. Cidades Inteligentes. GVexecutivo, V 12, N 2, Jul.Dez. 2013, p. 46-49.

- MACHADO, Carlos Augusto Alcântara. Constitucionalismo Fraternal. Revista Diálogos Possíveis, Salvador. 2014.

- MACHADO, Carlos Augusto Alcântara. A Fraternidade como Categoria Jurídica. Fundamentos e Alcance. Editora Appris; 1 ${ }^{a}$ edição, 2018.

- $\quad$ ROGERS, Everett M. Diffusion of Innovations (5th ed.). New York: Free Press. 2003.

- SACHS, Jeffrey. The age of sustainable development. New York: Columbia University Press, 2015.

- SACHS, Jeffrey D. “A energia elétrica sustentável”. Valor Econômico. São Paulo, 8 de abril de 2013. 
- SARLET, Ingo Wolfgang. A Eficácia dos Direitos Fundamentais. Porto Alegre: Livraria do Advogado Editora, 2004.

- SEN, Amartya. Desenvolvimento como liberdade. São Paulo: Companhia das Letras, 2000. 